\title{
LA REFORMA DE LA DEFENSA NACIONAL Y LAS FUERZAS ARMADAS ARGENTINAS EN DEMOCRACIA DURANTE LA DÉCADA DE 1990
}

\author{
A REFORMA DA DEFESA NACIONAL E DAS FORÇAS ARMADAS \\ ARGENTINAS EM DEMOCRACIA NA DÉCADA DE 1990
}

\section{Germán Soprano(*)}

Universidad Nacional de Quilmes, Quilmes (BUE), Argentina

\begin{abstract}
Resumen: Este trabajo tiene por objeto analisar las propuestas de reforma del sistema de defensa nacional y de las Fuerzas Armadas Argentinas en democracia, publicadas entre 1992 y 2001 en la revista "Seguridad Estratégica Regional en el 2000". Analizaremos artículos funcionarios y especialistas civiles y militares, argentinos y extranjeros, que fundamentaron la necesidad de esas reformas en el país para adecuarse a los cambios producidos en: a) un orden mundial post Guerra Fría; b) un escenario regional de estabilidad y paz en el Cono Sur; c) una agenda política que reclamaba la incorporación de la defensa a la "modernización del Estado".
\end{abstract}

Palabras clave: Reforma; Defensa nacional; Argentina.

Resumo: Este trabalho tem como objetivo analisar as propostas de reforma do sistema de defesa nacional e das Forças Armadas Argentinas na democracia, publicadas entre 1992 e 2001, na revista de "Seguridad Estratégica Regional en el 2000". Analisaremos artigos que foram escritos por funcionários e especialistas civis e militares, argentinos e estrangeiros, que consideraram a necessidade dessas reformas no país para se adaptar às mudanças em: a) uma ordem mundial pós Guerra Fria; (b) um cenário regional de estabilidade e paz no Cone Sul; (c) uma agenda política que apelou para a incorporação da defesa na "modernização do Estado".

Palavras-chave: Reforma; Defesa nacional; Argentina.

${ }^{*}$ ) Doctor, investigador del CONICET y profesor de la Universidad Nacional de Quilmes y de la Universidad Nacional de La Plata (Argentina).E-mail: gsoprano69@gmail.com. 


\section{INTRODUCCIÓN}

Este trabajo tiene por objeto analizar las propuestas de reforma del sistema de defensa nacional y de las Fuerzas Armadas Argentinas en democracia, publicadas entre 1992 y 2001 en la revista "Seguridad Estratégica Regional en el 2000", una revista de la época especializada en esos temas también conocida como "SER en el 2000". (1) Analizaremos artículos escritos por funcionarios y especialistas civiles y militares, argentinos y extranjeros, que fundamentaron la necesidad de esas reformas en el país para adecuarse a los cambios producidos en: a) un orden mundial post Guerra Fría con tensiones entre la hegemonía político-militar de Estados Unidos e iniciativas multilaterales; b) un escenario regional de estabilidad y paz en el Cono Sur, con supresión de hipótesis de conflicto vecinales y estímulo a la cooperación bilateral y multilateral en defensa y seguridad internacional; c) una agenda política del gobierno nacional que reclamaba la incorporación de la defensa a la denominada "modernización del Estado".

Los editores de la revista eran un pequeño y cohesionado grupo, liderado por el senador nacional Eduardo Vaca, perteneciente al Partido Justicialista o peronista y electo por la Capital Federal (ciudad de Buenos Aires). ${ }^{(2)}$ No obstante esta adscripción partidaria de Vaca y sus colaboradores, en el espacio institucional y de relaciones interpersonales construido entorno de "SER en el 2000" convergían intereses de individuos de diferentes partidos políticos, académicos, profesionales, funcionarios civiles y militares, argentinos y extranjeros, que participaron como autores de artículos y expositores en debates con el objetivo de definir una renovada agenda de defensa para la Argentina en democracia. ${ }^{(3)}$

\section{LOS ESCENARIOS INTERNACIONALES POST-GUERRA FRÍA: INESTABILIDADES, INCERTEZAS Y DESAFIOS}

Entre los analistas que publicaron en la revista existía la percepción de que la implosión de la Unión Soviética dejó a los Estados Unidos sin un oponente de peso político-militar equiparable y abrió escenarios internacionales inestables e inciertos en los que se esperaba un mayor protagonismo de agencias como Naciones Unidas, Unión Europea o el Mercosur. En esos escenarios, la defensa y seguridad internacional tendrían por objeto de atención "nuevas amenazas" como el narcotráfico, terrorismo, narcoterrorismo y otras manifestaciones del crimen transnacional organizado, así como fenómenos como pobreza y movimientos migratorios masivos, y catástrofes causadas por factores naturales o antrópicos - LÓPEZ y SAIN (2003); SAIN (2000); CANELO (2010); SOPRANO (2015).

(1) "SER en el 2000" publicó once números; cada uno tenía entre unas cien y ciento treinta páginas con las siguientes secciones: editorial, debates, ensayos, opinión, documentos, reseñas.

(2) Para un análisis del liderazgo político de Eduardo Vaca, del equipo editorial de "SER en el 2000", y de los participantes de los seminarios de discusión organizados por el mismo, remitimos al estudio de SOPRANO (2013).

(3) El presente artículo es parte de una investigación sobre política de defensa, educación y configuración profesional en las Fuerzas Armadas Argentinas entre 1983 y el presente. Su contenido no agota la valía del material publicado en la revista, de modo que se continuará profundizando en su estudio en futuros trabajos. 
Pero a pesar de esos cambios, persistían unos instrumentos militares de la defensa configurados para atender "amenazas convencionales" potencialmente provocadas por Fuerzas Armadas estatales. Particularmente en Suramérica los militares se resistían explícitamente a reconvertirse en fuerzas de seguridad o policiales, organizaciones de desarrollo y defensa civil. En este sentido, no debe sobreestimarse la influencia norteamericana promoviendo reformas en post de esas "nuevas amenazas" en las conducciones políticas y castrenses de esos países; pues si bien dichas conducciones se manifestaban a favor de la incorporación de esas amenazas como "misiones secundarias" o "subsidiarias" de sus Fuerzas Armadas, al mismo tiempo, no preveían renunciar a sus capacidades militares "convencionales" en cumplimiento de su "misión principal", ya sea por reconocer la supervivencia de conflictos interestatales vecinales, eventuales amenazas de países extra-regionales, o bien como consecuencia de la reproducción de intereses y comportamientos burocráticos o corporativos castrenses. También cabe destacar que para políticos, militares y académicos argentinos la construcción de confianza mutua y cooperación en defensa y seguridad internacional en la región era evaluada como un proceso deseable, pero lento y conflictivo, tal como comprobaron en 1995 con la "Guerra del Cenepa" que enfrentó a Perú y Ecuador.

En "El concepto de suficiencia defensiva", publicado en n. 1 de la revista en marzo de 1992, Virgilio Beltrán, mayor auditor en situación de retiro e investigador del Instituto Di Tella y Secretario del Centro de Estudios Estratégicos del Ejército, caracterizaba a la Argentina como un país aspirante a "potencia mediana" que abandonó sus hipótesis de conflicto con Brasil y Chile. Se preguntaba por ello: ¿Cuánta fuerza debía disponer la Argentina para estar seguros sin amenazar a otros o disuadir a potenciales agresores? ¿Cuál sería un dispositivo de defensa suficiente que demostrara ausencia de intensiones agresivas y fuese capaz producir a un eventual agresor costos y pérdidas que no pueda o no estuviera dispuesto a afrontar? En definitiva: ¿qué debía entenderse por "suficiencia defensiva"? Su respuesta era que este último concepto comprendía la "defensa territorial", "defensa geofísica" del espacio terrestre, aéreo y marítimo, y la "limitación de la capacidad ofensiva". Esto conllevaba el compromiso a renunciar a dos capacidades: "atacar por sorpresa a sus vecinos (u otros potenciales adversarios)" e "implementar una penetración en profundidad y/o en gran escala en el territorio de sus vecinos (u otros potenciales adversarios)". Se requería, pues, "fuerzas para armar", "versátiles", "flexibles", con "gran movilidad, potencia de fuego y con capacidad ofensiva" (BELTRÁN, 1992, p. 40-41).

Ahora bien, si la política de defensa argentina consensuada en la Ley de Defensa Nacional de 1988 era "defensiva" y "autónoma", también lo era "cooperativa". Por ello Beltrán consideraba, además, preciso: a) generar "confianza mutua" con países con los que se tuviera conflictos; b) crear "centros de prevención de conflictos" para disponer canales de comunicación y desescalar conflictos por vía diplomática; c) desarrollar la "cooperación" e "interoperabilidad" militar en "misiones bajo autoridad internacional" y "sistemas de seguridad mutua" contra "agresiones extra-sistema"; d) impulsar "emprendimientos logísticos internacionales" con interdependencia en la producción de armamentos y equipos entre países cooperantes (BELTRÁN, 1992, p. 41). 
En el n. 1 también se publicó el artículo del Jefe de Estado Mayor General de la Armada: "Evitar la guerra y mantener la paz". Allí el almirante Jorge Osvaldo Ferrer instalaba temas sobre seguridad internacional y defensa que tenían más correspondencia con la agenda hemisférica de los Estados Unidos que con la Ley de Defensa Nacional que prescribía una estricta separación entre defensa nacional y seguridad interior, restringiendo el instrumento militar exclusivamente contra agresiones externas. Reconocía que en la "reconfortante confluencia entre democracia como sistema político y la libertad económica" persistían "acechanzas y peligros imprescindibles de afrontar". Que ese mundo donde las Fuerzas Armadas debían intervenir para "evitar la guerra y mantener la paz" no carecía de conflictos y amenazas, pues además de la "ancestral tendencia del uso de la violencia" existían problemas como "superpoblación, el hambre y la miseria", "limitación de recursos y energía", "daño ecológico", "imperio subterráneo de la cocaína", "fanatismo religioso o el extremismo ecologista", "choques por motivos ideológicos, religiosos o promovidos por ambición o reivindicaciones". Esos problemas habilitaban el accionar de organizaciones situadas por "fuera de las estructuras del Estado-nación, adquiriendo creciente poder, incluso a expensas de las mismas". ¿Qué tipo de instrumento militar necesitaban los Estados nacionales para enfrentarlos? Ferrer decía que unos que, además de garantizar la defensa nacional, participen del "deber protagónico de las naciones" de proyectarse a los "escenarios mundiales, por más remotos que éstos sean", tal como ocurriera con el involucramiento de las Fuerzas Armadas Argentinas en la Guerra del Golfo (1990-1991) en el marco de una acción militar de la ONU con fuerzas multinacionales (FERRER, 1992, p. 81-82). Se preguntaba asimismo si intervenir militarmente en conflictos lejanos y disponer de fuerzas con "capacidad de proyección" era un objetivo sólo para "países poderosos", o bien si "países en desarrollo" como Argentina debían sopesar esa alternativa. Y respondía positivamente por dos razones:

La primera, para gozar de los beneficios de la libertad, la paz y el desarrollo, deben asumirse los riesgos y responsabilidades para su defensa. La segunda es que, así como la actitud ante la vida condiciona el futuro de los seres humanos, la actitud ante el mundo que asuma cada nación, condicionará su futuro. La capacidad de proyección podrá ser un esfuerzo organizativo y económico, pero el protagonismo es sin duda alguna, un beneficio superior para la nación participante [...] Toda nación que asuma su rol protagónico para bien de la humanidad, debe disponer permanentemente organizada y alistada, una fuerza de proyección de dimensión moderada y acorde con el potencial de cada estado. (FERRER, 1992, p. 82).

Para asegurar el cumplimiento de esos compromisos era precisa una "alianza estratégica" entre los países miembros de la Organización de Estados Americanos, estableciendo una "vinculación efectiva" a nivel de la Junta Interamericana de Defensa-JID, asumiendo que en un mundo post Guerra Fría con escenarios cambiantes donde el "enemigo de ayer" devenía en "aliado" o viceversa, debía contarse con un instrumento militar flexible, no definido por "determinismos ni enemigos prefijados", ni debía "prepararse para una guerra determinada, sino para ser útil al gobierno en el manejo de crisis derivadas de conflictos" y con capacidad de "disuasión creíble". Por tanto, los Estados no podían renunciar a disponer de Fuerzas Armadas con capacidades efectivas para garantizar la defensa nacional, ya que inclusive "los países más pequeños tienen obligación 
moral de poseer cierta capacidad de disuasión, porque aún cuando sean agredidos por fuerzas muy superiores, deben asegurar la resistencia imprescindible para dar tiempo a la intervención de la comunidad internacional" (FERRER, 1992, p. 82).

Por último, el almirante Ferrer sostenía que la Armada Argentina también tenía misiones que cumplir como parte de sus compromisos con la defensa nacional en tiempos de paz, pues:

[...] cada vez con más intensidad las flotas pesqueras incursoras en zonas de interés nacional, utilizan equipos y procedimientos de grado de sofisticación creciente, obligando a encarar el control del mar, con medios y planes compatibles con la misión bélica de las unidades. Un caso similar puede encontrarse en las tareas que las Fuerzas Armadas cumplen en varios países, en apoyo a las misiones policiales contra el narcotráfico (FERRER, 1992, p. 83).

Por su parte, en "Las misiones de los Ejércitos" el teniente general Martín Balza, Jefe del Estado Mayor General del Ejército, definía unos escenarios internacionales caracterizados por cambios provocados por la transición desde un "mundo bipolar" "supuestamente predecible" hacia otro "multipolar, fracturado e inestable" e "interdependiente". En consecuencia, reconocía simultáneamente la existencia a nivel regional y global de "amenazas convencionales" interestatales y la emergencia de otras "nuevas" tales como:

[...] las tensiones demográficas, los espacios vacíos, las disputas por los recursos y los mercados, la presencia de enclaves coloniales irritantes, la desigualdad de oportunidades para el desarrollo económico, los problemas limítrofes territoriales no resueltos, los sistemas sociales atacados por la corrupción sistemática, la emergencia de nacionalismos disgregacionistas, la intemperancia religiosa, las amenazas ecológicas, la proliferación de armamentos, la producción y tráfico de drogas y otros flagelos (BALZA, 1992, p. 85).(4)

Para Balza los Ejércitos poseían, por un lado, una "misión general y primaria" como instrumento militar "disuasivo de defensa creíble" destinado a preservar "los intereses vitales de la Nación"; y, por otro, "roles secundarios" o "subsidiarios" mediante los cuales participaban "del progreso y bienestar de los pueblos" teniendo en cuenta las "restricciones propias de la ley" de Defensa Nacional y de Seguridad Interior vigentes en la Argentina. Reconocía, no obstante, que en el escenario global pos Guerra Fría y regional de supresión de conflictos vecinales en el Cono Sur los "roles secundarios" ofrecían "mejores posibilidades para avanzar hacia un sistema de seguridad de complementación regional". ¿Cuáles serían esos roles secundarios?

1. Participar de misiones de organizaciones militares de paz. 2. Prestar apoyo logístico, de asesoramiento técnico, de comunicaciones y de transporte en la lucha contra la narcosubversión. 3. Colaborar con medios y personal para hacer frente a desastres naturales que afecten a los bienes y a las personas. 4. Brindar apoyo a la comunidad explotando su capacidad de organización y técnica operacional (BALZA, 1992, p. 85-86).

(4) Las "nuevas amenazas" también fueron objeto de "Buscando nuevos roles para los Ejércitos de América Latina", publicado en el n. 4 de la revista de septiembre de 1993 por Virgilio Beltrán - Subsecretario de Política y Estrategia del Ministerio de Defensa. 
Cuando Balza sumaba a los militares a las tareas de apoyo logístico, en comunicaciones, transporte y sanitarias efectuadas por las fuerzas de seguridad en cumplimiento la "lucha contra el narcotráfico", no violentaba abiertamente la Ley de Defensa Nacional. Sin embargo, alentaba expectativas por securitizar las funciones militares. En este sentido - como han destacado Marcelo Sain (2000) y Paula Canelo (2010) - durante la década de 1990 decretos y resoluciones de menor jerarquía sancionadas por el gobierno nacional y la conducción militar argentina tendieron a horadar la taxativa diferenciación entre defensa nacional y seguridad interior establecidas por las leyes homónimas del Congreso Nacional en 1988 y $1991^{(5)}$.

Balza se manifestaba a favor de la integración regional y conformación de alianzas o bloques regionales como la "zona de libre comercio" impulsada por los Estados Unidos. Pero advertía que la integración en el plano militar y, en particular, de los Ejércitos sería "dificultosa" ante el evidente "desequilibrio estratégico" de fuerzas de los diferentes países y, en especial, en relación con Estados Unidos. ${ }^{(6)}$ Se preguntaba ¿Cómo podría producirse esa complementación entre Ejércitos americanos? La concebía fundamentalmente en torno de "misiones", "funciones" o "roles secundarios", esto es "en el campo científico y tecnológico de la educación, del apoyo a la lucha contra el narcotráfico y ante desastres y catástrofes naturales". En tanto que la "función principal" o "misiones tradicionales y trascendentes de los Ejércitos" relativas a la producción de un "efecto de disuasión que el instrumento militar debe proporcionar ante la amenaza y agresión", continuaría siendo una "responsabilidad indelegable y no subrogable de cada Estado y de cada Ejército" (BALZA, 1992, p. 87).

Con esto último Balza ponía un límite a los alcances de la cooperación militar. Por el contrario, dirigentes políticos del Partido Justicialista y la Unión Cívica Radical contemporáneos del Jefe de Estado Mayor General del Ejército, advertían sobre la imposibilidad de los países del Cono Sur o América del Sur de asegurar su defensa en forma exclusivamente autónoma ante eventuales amenazas estatales externas de potencias extra-regionales. Por ello, los legisladores nacionales - como Eduardo Vaca y Horacio Jaunarena - que impulsaron la Ley de Reestructuración de las Fuerzas Armadas sancionada en 1998 en el Congreso Nacional, incorporaron en su articulado la propuesta de conformar un sistema de defensa regional a nivel del Mercosur. ${ }^{(7)}$ En definitiva, en los posicionamientos expresados por Balza y aquellos contenidos en la mencionada ley, se manifestaban dos concepciones de la defensa nacional y la seguridad internacional diferentes: una en favor de la cooperación bilateral o multilateral y otra en pos de la integración regional. ${ }^{(8)}$

(5) Asimismo que la Ley de Defensa Nacional permaneciera sin reglamentarse hasta 2006, es un dato expresivo de cómo sus postulados estaban permanentemente expuestos a ser negados en la práctica.

(6) A diferencia del almirante Ferrer, en el artículo "La seguridad regional" del n. 4 de septiembre de 1993, Balza se mostraba crítico del Tratado Interamericano de Defensa y apoyaba el diseño de un "sistema regional nuevo" de cooperación en defensa a nivel americano o hemisférico. También denunció la existencia de "enclaves coloniales irritantes". Recordemos que Estados Unidos desatendió el TIAR en la Guerra de Malvinas entre la Argentina y el Reino Unido, toda vez que estuvo lejos de apoyar la causa argentina contra la amenaza extra-continental británica.

(7) Para un análisis de la elaboración de la Ley de Reestructuración de las Fuerzas Armadas: MARTÍNEZ (2002).

(8) En ALVES SOARES y SOPRANO (2014) se ha efectuado un análisis comparado de esas concepciones en los casos de la Argentina y Brasil desde las décadas de 1990 al presente. 
Otra importante misión subsidiaria o secundaria de los militares eran las misiones de paz. Como ha demostrado Alejandro Simonoff (2010), los posicionamientos de la política externa argentina ante esos nuevos escenarios redundaron desde 1990 en un incremento histórico de la participación de las Fuerzas Armadas Argentinas en operaciones bajo mandato de las Naciones Unidas. Esto quedó reflejado en "SER en el 2000" con un artículo en el n. 5 publicado en marzo de 1994 - "La participación argentina en las operaciones de paz" - del embajador Hernán Massini Ezcurra, Director de Organismos Internacionales del Ministerio de Relaciones Exteriores y Culto de la Argentina. Su autor consideraba que las misiones de paz habilitaron no sólo el cumplimiento de tareas militares sino de otras del orden civil como la "creación de nuevas administraciones", garantizar "procesos electorales limpios", "asistencia hospitalaria y alimenticia, derechos humanos, mejora del sistema administrativo y aduanero, creación de nuevas fuerzas policiales, modificación de la legislación etc." (MASSINI EZCURRA, 1994, p. 24-25).

Finalmente el artículo de Gabriel Marcella - profesor del US Army War College, ex Consejero de Asuntos Internacionales del Comandante en Jefe del Comando Sur de los Estados Unidos y miembro del Consejo Honorario Internacional de la revista - fue publicado en el №5 de marzo de 1995: "Misiones futuras de las Fuerzas Armadas Latinoamericanas y política de los Estados Unidos". Asumía que el fin de la Guerra Fría produjo un radical cambio en las concepciones norteamericana e internacional acerca de la seguridad y la defensa. La tradicional alianza de los Estados Unidos con las Fuerzas Armadas latinoamericanas "contra el comunismo" debía ser superada por la definición de nuevas concepciones y misiones militares en el marco de la identificación de amenazas como el "narcotráfico", "terrorismo" y el "desafío ecológico". ¿Cuál sería entonces la nueva política hemisférica de los Estados Unidos? Para explicarla Marcella citaba al Secretario de Estado Asistente para Asuntos Interamericanos, Bernard Aronson:

Los Estados Unidos no buscan una nueva hegemonía en el mundo. Los Estados Unidos no quieren debilitar o disminuir las fuerzas armadas para su ventaja; no están tratando de desmilitarizar el hemisferio. Las naciones tienen un derecho soberano a tener fuerzas armadas; la reorganización, como los EEUU también están haciéndolo, es un paso lógico. En la guerra contra el narcotráfico no existe señal por parte de los EEUU de trabajar con la policía contra los militares. El tráfico de drogas es primariamente un problema policial. Sin embargo, dado el hecho de que los traficantes son una nueva y más sofisticada forma de criminales, los militares necesitan ayudar a la policía (MARCELLA, 1994, p. 50).

Vemos que Aronson no vedaba a los países latinoamericanos la posesión de Fuerzas Armadas, pero su énfasis en la reconversión de las mismas para cumplir funciones de seguridad interior y orden público fueron rechazados, entre otros autores de artículos, por el general de división (retirado) Manoel Teixeira, ex-Subjefe del Estado Mayor del Ejército Brasileño. En su "Sociedad, Fuerzas Armadas y Política de Defensa en Brasil", del n. 2 de septiembre de 1992, decía: "La impresión que yo tengo es que a los Estados Unidos le interesaría mucho que no hubiera más Fuerzas Armadas en América Latina, y sí un cuerpo de Gendarmería colectivo, con la seguridad externa dada por los Estados Unidos". Entendía pues que el abandono o debilitamiento de las misiones de defensa externa desperfilaba o directamente anulaba las capacidades militares de las Fuerzas 
Armadas. Y advertía terminantemente que los militares no podían privilegiar en sus misiones "los problemas de pobreza", "complementar el trabajo de la policía", o "participar de la lucha contra el narcotráfico" (TEIXEIRA, 1992, p. 30).

Por el contrario, para Marcella las Fuerzas Armadas Latinoamericanas debían cumplir tareas de apoyo a la seguridad, educativas, de salud pública o efectuar obras de infraestructura como lo habían hecho en los Estados Unidos en el siglo XIX. También debían participar de la "lucha contra el narcotráfico" respaldando a fuerzas policiales "dentro de los límites constitucionales" y cuando "la policía puede no ser capaz de cumplir con la tarea contra un enemigo que puede superarla en poder de fuego y maniobra". Y de igual modo debían involucrarse en la lucha "contrainsurgente", pues los intereses de la "guerrilla" eran convergentes con el narcotráfico. Ahora bien, la aceptación de esas misiones contra "nuevas amenazas" debía completarse - decía - con el reconocimiento de una cuestión básica: los Estados Unidos debían aceptar que los militares latinoamericanos rechazaban los "roles policiales", aún cuando reconocieran que debían participar del "esfuerzo nacional contra los traficantes" (MARCELLA, 1994, p. 52-53).

Asimismo Marcella sostenía que el cumplimiento simultáneo de "misiones de la seguridad externa e interna" había existido siempre en las Fuerzas Armadas Latinoamericanas. Y si bien los casos de la Argentina o Brasil expresaban situaciones ideales de separación entre defensa nacional y seguridad interior, en "la práctica en cualquier parte es bastante diferente". Así pues, decía que en Brasil el Comando Militar del Amazonas construía carreteras, aeropuertos y escuelas, proveía salud, transporte y correo, además de seguridad interna y externa. No obstante, los Estados nacionales debían establecer límites a la participación de las Fuerzas Armadas en el proceso de "construcción de la nación", pues con esas funciones no debían reemplazar en forma permanente a las organizaciones civiles encargadas de proveer esos servicios. ¿Cuáles eran entonces las tareas efectivas de las Fuerzas Armadas Latinoamericanas? Marcella respondía:

Defender las fronteras, zonas marítimas y espacio aéreo. Controlar la emergencia de insurrecciones. Ayudar al desarrollo de infraestructuras nacionales sin competir con los civiles en actividades que éstos puedan cumplir. Ayudar a las autoridades civiles a preservar los recursos naturales y luchar contra la contaminación ambiental. Asistir en los desastres naturales, misiones de mantenimiento de la paz internacionales, y una modesta participación en operaciones multinacionales [...]. Proveer un símbolo de la nacionalidad y de la soberanía [...]. Asistir a las autoridades de ejecución de la ley en los esfuerzos de la lucha contra el narcotráfico" (MARCELLA, 1994, p. 54).

Estas ideas de Marcella no se adecuaban bien a la imagen del estereotipo del funcionario norteamericano que procuraba securitizar unilateralmente las misiones de las Fuerzas Armadas Latinoamericanas, pues si los militares se desentendían de su "responsabilidad en la defensa externa", "enfrentar las insurgencias" y de la "lucha contra los narcotraficantes" y "terroristas", serían reducidos - decía - al perfil de simples "tropas de boy scouts y bandas municipales" (MARCELLA, 1994, p.55). Por ello cuestionaba al Comando Sur cuando ponderaba "la guerra contra las drogas" como eje excluyente de la cooperación militar, pues esa política hemisférica desatendía el "centro de los intereses 
del profesional militar latinoamericano" orientado hacia la defensa externa de sus países. En este punto, Marcella coincidía con los Jefes de Estado Mayor del Ejército y la Armada Argentina, y con el ex-Subjefe del Estado Mayor del Ejército Brasileño.

\section{EL ESCENARIO REGIONAL DE ESTABILIDAD, PAZ Y COOPERACIÓN EN EL CONO SUR}

Durante la Segunda Guerra Mundial los Estados Unidos estimularon el desarrollo de una política de seguridad para el continente americano, primero previendo contrarrestar amenazas de países del Eje y luego de la Unión Soviética. Y aunque esa política subsumía bajo su liderazgo todos los países de la región, las hipótesis de conflicto vecinales orientaban las políticas de defensa nacional y el planeamiento militar de estos últimos.

En el caso de la Argentina desde finales del siglo XIX las amenazas vecinales eran Brasil y Chile. En la década de 1970 durante las dictaduras que gobernaban Argentina y Brasil se resolvieron, particularmente, los conflictos en torno de la construcción de represas hidroeléctricas en la Cuenta del Río Paraná. Ese proceso de negociación fue consagrado por los presidentes Raúl Alfonsín y José Sarney en el Acta de Foz do Iguazú en noviembre de 1985, que sentó las bases para el Mercosur creado en 1991. Pero a pesar del rol significativo que cupo a esos dos líderes democráticos en la voluntad de cooperación e integración, no debe omitirse que para entonces las asimetrías económicas entre Argentina y Brasil se habían ampliado a favor de este último y, en consecuencia, el primero fue desplazado de la disputa por el liderazgo en el Cono Sur, tal como han destacado entre otros especialistas: RUSSELL y TOKATLIÁN (2003); MONIZ BANDEIRA (2004); DEVOTO y FAUSTO (2008); y RAPOPORT y MADRID (2011).

Por el contrario, las relaciones entre Argentina y Chile habían tenido una rivalidad histórica más marcada (LACOSTE, 2003), que alcanzó la antesala de un conflicto armado en diciembre de 1978 y que supuso el apoyo político-militar del país trasandino a Gran Bretaña durante la Guerra de Malvinas (BICHENO, 2009). Recién con los acuerdos alcanzados por los presidentes democráticos Carlos Menem y Patricio Ailwyn en agosto de 1991, que permitieron resolver los litigios fronterizos en las áreas con Hielos Continentales de la Cordillera de los Andes, las relaciones bilaterales comenzaron a propiciar la cooperación (RUNZA, 2004). Ahora bien, el seguimiento de artículos publicados en la revista demuestra que ese proceso de construcción de confianza mutua Argentina-Chile era orientado por una vocación a favor de la cooperación, pero fuertemente connotado por la persistencia de desconfianzas. En la perspectiva de los argentinos existía la certeza de que en Chile había grupos políticos y militares que continuaban instigando la rivalidad vecinal y el militarismo. Y no escapaba a ese diagnóstico el hecho que el general Augusto Pinochet continuara siendo (hasta 1998) Comandante en Jefe de las Fuerzas Armadas y ejerciera una tutela decisiva sobre la política de defensa y militar chilena.

En "Identidad nacional e integración regional", en el n. 2 de septiembre de 1992, el senador nacional Eduardo Vaca hacía un balance de las intervenciones de participantes del "Simposio de Estudios Estratégicos de los Estados Mayores de Argentina, Brasil, 
Uruguay y Paraguay" realizado en Buenos Aires en junio de 1992. Destacaba que algunos expositores sostuvieron que

"[...] si el proceso de integración no se realiza con suma cautela, puede provocar graves riesgos a identidades nacionales aún muy frágiles"; en tanto que, contrariamente, otros, señalaron que "sólo en la integración puede ser posible la defensa de esas identidades frente a la magnitud de los desafíos que la situación internacional provoca (VACA, 1993, p. 5-6)”.

Para Vaca ambos posicionamientos expresaban "algo de verdad", pero entendía que en el Cono Sur era preciso definir "proyectos de nación y región” que no fueran antagónicos (VACA, 1992, p. 5-6).

En ese número también se publicaron dos textos sobre las relaciones entre Brasil y Argentina, y Chile y Argentina. El primero - "Sociedad, Fuerzas Armadas y Política de Defensa en Brasil" - era del general de división (R) Manoel Teixeira, ex-Subjefe del Estado Mayor del Ejército Brasileño y Director del Instituto Liberal de São Paulo. Sostenía que Brasil había efectuado un estudio prospectivo sobre escenarios para los próximos quince años: tres escenarios mostraban a Argentina y el Brasil avanzando hacia un "sistema de cooperación", y dos eran "catastróficos" comprendiendo conflictos entre ambos. Si ocurrían los tres primeros preguntaba: ¿Cómo puede haber un escenario de cooperación si los dos países mantienen en sus fronteras dispositivos militares "frente a frente?". La persistencia de esos dispositivos se debía a que:

Durante 80 años, desde que las escuelas [de Guerra o Comando de las Fuerzas Armadas] están bien organizadas, ven como doctrina la hipótesis de guerra de Brasil con Argentina y viceversa. Los oficiales brasileños que hacían los cursos de la Escuela de Estado Mayor aquí, en Buenos Aires, hace unos cuatro años atrás, participaban en ejercicios donde el enemigo era Brasil, y esto no se ocultaba a nuestros oficiales. En Brasil hacíamos una diferencia y lo llamábamos enemigo del sur, o los nombrábamos con un color. Las escuelas tienen esa influencia que acabo de mencionar; entonces está enraizado en la cabeza de los militares de ambos países que entre sí son enemigos, y que son enemigos que conviven muy bien y que esperan que nunca se produzca una guerra entre ellos. Por lo tanto, para hacer un cambio hay que hacer primero un cambio de mentalidad, porque todo está muy aferrado en los militares de ambos lados. Tendría que producirse un cambio en los programas de estudio de las escuelas, donde se vea un escenario entre nuestros países de cooperación, y no de conflicto [...]. Un joven que está en la escuela militar de perfeccionamiento tiene que considerar a Argentina como un aliado para hacer frente a enemigos más graves, que no están en el hemisferio sur seguramente [...]. De todo lo que está ocurriendo en el Norte con relación al Sur sólo hay una salida; que Brasil y Argentina estén juntos tanto en recursos humanos como en tecnología, en el Mercosur. Aislados no tienen posibilidad de supervivencia, no estamos en condiciones de participar de lo que está ocurriendo en el resto del mundo. Debemos estar juntos (TEIXEIRA, 1992, p. 32-34).

El otro artículo, "El debate sobre integración regional y defensa en Chile" de Daniel Prieto Vidal, consideraba que Chile y Argentina podían coordinar la "defensa conjunta del Atlántico Sur, del Pacífico Sur, de los pasos australes y de la Antártida"; pero para alcanzar ese objetivo debían terminar con las rivalidades vecinales y diseñar entrenamientos conjuntos para objetivos comunes. Esas coordinaciones debían proponer- 
se, además, incorporar a Uruguay y Paraguay en una "alianza denominada Cono Sur", al Brasil y los países del Pacto Andino, procurando la coordinación de "tres bloques" Cono Sur+Brasil+Pacto Andino - en una "hipótesis de defensa suramericana conjunta" contra las amenazas del "terrorismo, la defensa de las vías de comunicación marítima y las operaciones de vigilancia aérea de carácter subcontinental" (PRIETO VIDAL, 1992, p. 37). Nótese que este autor no incluía la cooperación para la defensa y seguridad regional contra amenazas estatales hemisféricas o de potencias extra-regionales. Pero Prieto Vidal imaginaba, al mismo tiempo, otro escenario donde la "coordinación suramericana" no prosperaría y surgieran "amenazas que nos obliguen a enfrentar una agresión vecinal unilateral, bilateral o trilateral" (PRIETO VIDAL, 1992, p. 37-38). Conviene reparar en este potencial escenario bélico previsto por este autor, a fin de advertir que las iniciativas de la cooperación e integración en el Cono Sur no desconsideraban la persistencia de las tradicionales hipótesis de conflicto vecinales. Es por ello que las Fuerzas Armadas de los países de la región no renunciaban al cumplimiento de su misión principal, esto es, conjurar agresiones convencionales de otros Estados, en pos de la adopción unilateral de misiones secundarias.

El n. 8 de "SER en el 2000", de octubre de 1995, estaba referido a la reestructuración del sistema de defensa en el proceso de cooperación e integración del Cono Sur. El artículo del senador nacional Vaca, "Reestructuración del sistema de defensa", abrió el debate con una importante definición: la restructuración no debía confundirse con una "política global de contención del gasto público". Si entonces no era un mero ajuste presupuestario ¿Cómo debería ser esa reestructuración en la esfera de la defensa y las Fuerzas Armadas? En primer término, Vaca consideraba que la Argentina no debía prever la "defensa del interés nacional más allá del ámbito nacional y subregional", pues no contaba con importantes inversiones, ni una masa de población residiendo fuera de sus fronteras; en consecuencia, no requería de un instrumento militar con capacidades para proyectar poder a nivel extra-regional o global. Y ello no sólo en virtud de que su política de defensa era una disuasiva y defensiva, sino porque el país disponía en su territorio de insumos alimenticios y energéticos básicos y las mercancías que exportaba e importaba no circulaban por regiones del mundo donde debiera contarse con recursos militares propios para resguardarlas. Por último, consideraba que aunque la Argentina tenía necesidades científico-tecnológicas que no podían solventarse en forma autónoma, su satisfacción tampoco podía obtenerse por medio de la fuerza armada.

En segundo lugar, Vaca entendía, por un lado, que la cooperación e integración en el Cono Sur tenía carácter estratégico para Argentina, no sólo por razones políticas, económicas y culturales, sino porque era su mejor reaseguro en términos de defensa nacional y seguridad internacional. Pero, por otro lado, asumía que los progresos en materia de cooperación e integración regional no estaban exentos de conflictos ni potenciales amenazas, pues:

[...] nuestros mayores riesgos están en la región [...] cualquier agresión militar provendrá casi con seguridad del territorio de un vecino, aunque no sea por su voluntad. De allí la importancia de extender nuestra frontera de seguridad mediante acuerdos con los vecinos [...]. La diferencia se torna sutil pero es necesario marcarla, porque ya no se trata de disponer de un instrumento militar que sea capaz de responder a una agresión brasileña o chilena como lo hacíamos en el pasado (VACA, 1995, p. 10). 
Por último, para Vaca la vigencia de regímenes democráticos en el Cono Sur constituía una garantía adicional contra cualquier cambio sorpresivo en las relaciones vecinales, porque "en las democracias no hay decisiones de un día para otro y sin el necesario requerimiento y consenso político". El caso particular del conflicto entre Perú y Ecuador en febrero de 1995 - la "Guerra del Cenepa" - no contradecía su hipótesis, pues - decía - fue un fenómeno restringido a una región militarizada y operaron mecanismos multilaterales que contuvieron la escalada bélica.

El debate que abrió su exposición fue publicado y ofrece una idea sobre los posicionamientos que suscitó. Un participante no identificado dijo que se podía discutir el tamaño, dimensión, objetivos y proyección militar argentina, pero que de ninguna manera se debía dudar de su necesidad. Esta intervención merece un comentario pues expresaba la existencia durante la década de 1990 de corrientes de opinión en sectores políticos y de la sociedad argentina que cuestionaban a las Fuerzas Armadas por asociarlas con el desprestigio del gobierno dictatorial del "Proceso de Reorganización Nacional" de 19761983 y su derrota en la Guerra de Malvinas en 1982, con los crímenes de lesa humanidad cometidos por aquel gobierno de facto, y con los "levantamientos militares carapintada" contra autoridades democráticas ocurridos entre 1987 y 1990. ${ }^{(9)}$

Por su parte, el economista norteamericano, profesor en la Universidad Nacional de Quilmes, Thomas Scheetz, destacó positivamente el abandono de las hipótesis de conflicto vecinales en el Cono Sur, pero reclamó que era necesaria la definición de "contingencias creíbles de la región" que orientaran la reestructuración de la defensa y el planeamiento militar. En tanto que José Manuel Ugarte - histórico asesor parlamentario del bloque de la Unión Cívica Radical - dijo que el proceso de cooperación e integración en esa región tenía en Chile un actor potencialmente conflictivo, debido a que la "inestabilidad política" en las relaciones civiles-militares existentes en ese país podía dar lugar a una "aventura militar" (VACA, 1995, p.15-16). (10) Scheetz y Ugarte no eran belicistas y eran explícitos partidarios de la cooperación e integración bilateral y/o regional, pero advertían - como también lo hicieron el almirante (retirado) Fernando García y el editor Luis Tibiletti - que era preciso avanzar con precaución en la reestructuración del sistema de defensa argentino, pues reconocían la persistencia de actores que podían instigar la continuidad de hipótesis de conflicto vecinales. Para ellos Chile era una preocupación principal, no así Brasil.

\section{LA DEFENSA NACIONAL EN LA "MODERNIZACIÓN DEL ESTADO"}

Las políticas neoliberales de ajuste fiscal y de reforma o "modernización del Estado" durante las presidencias de Carlos Menem (1989-1995 y 1995-1999) alcanzaron el área de defensa nacional y las Fuerzas Armadas, comprendiendo el cierre y relocalización

(9) Sobre las percepciones de sectores políticos y de la sociedad argentina sobre los militares: CANELO (2010).

(10) Si bien Ugarte no lo explicitaba, por "aventura militar" en Chile podría interpretarse un eventual golpe castrense en ese país o las pretensiones de sus Fuerzas Armadas de sostener privilegios políticos y corporativos lesivos para el sistema democrático; o bien una potencial agresión militar a países vecinos con el objeto de estimular sentimientos nacionalistas de la población chilena y apoyos a sus Fuerzas Armadas. 
de unidades, reducción de compras de equipamiento y de medios, cierre y/o privatización de empresas del sector. Y si bien la política económica "neoliberal” y la política externa de "alineamiento automático" con los Estados Unidos fueron determinantes clave en la orientación de la reestructuración en el sector (POCZYNOK, 2014), nuestro análisis no debe desconsiderar las propuestas específicas del sector defensa propiciadas por oficiales superiores de las Fuerzas Armadas y funcionarios civiles del Ministerio de Defensa que publicaron artículos en "SER en el 2000". En este sentido, estas intervenciones tenían por fin reorientar la discusión desde las más simples propuestas de recorte fiscal (acrecentadas por la debilidad política y corporativa de las Fuerzas Armadas y por un escenario de paz y de estabilidad en el Cono Sur) hacia otras de reestructuración que permitieran afrontar los desafíos para el siglo XXI.

Así pues, en el n. 3 de mayo de 1993 aparecieron tres artículos sobre el diseño futuro de las Fuerzas Armadas Argentinas; cada uno con la autoría de un oficial superior. En "El Ejército Argentino en el Futuro", el Jefe de Estado Mayor del Ejército, teniente general Martín Balza concebía su fuerza como una destinada afrontar las incertezas del "nuevo orden mundial", sirviéndose de la "incorporación de tecnología" con el objetivo de reemplazar sus tradicionales fortalezas cuantitativas por la "preeminencia de lo cualitativo". Por ello decía:

[...] imaginamos organizaciones terrestres reducidas, potentes y muy móviles (blindadas, mecanizadas, aeromóviles, y aerotransportadas), operando en amplios espacios bajo el paraguas de adecuados medios de vigilancia (satélites, aeroterrestres y terrestres de gran complejidad). 1) Cuantitativamente reducidas, pero cualitativamente superiores. 2) Con gran movilidad estratégica y táctica, y menos aferradas a la servidumbre que actualmente le impone el terreno. 3) Que operarán a 'tiempo completo’, superando con un profuso empleo de navegadores inerciales y visores térmicos o de intensificación de imágenes, la actual restricción que la 'opacidad' del campo de combate impone. 4) Fortalecidas en cuanto a la letalidad de sus medios: helicópteros de ataque y asalto, armas inteligentes ('dispara y olvídate'). 5) Dotadas de medios sustentados por tecnología sensitiva superior. 6) Elevada capacidad de interoperabilidad y compatibilidad básica. 7) Aptas para la batalla conjunta. 8) Altamente dotadas de potencia de choque y maniobrabilidad de los fuegos. 9) Con capacidad de responder a una amplia gama de eventualidades, incluida la participación activa del Ejército en distintos escenarios dentro del marco de las Organizaciones Militares de Paz de las Naciones Unidas. 10) Apoyadas por la electrónica aplicada (comando, control, comunicaciones e inteligencia; optrónica; visión nocturna; radárica), inteligencia artificial (modelización y simulación asistida), tecnología satelital (posicionamiento, adquisición, transmisión, y procesamiento) (BALZA, 1993b, p. 20).

Ese proyecto de "modernización" del Ejército postulado por Balza tuvo en la década de 1990 (y aún después) una concreción módica, no sólo por la relativamente reducida disponibilidad de recursos presupuestarios destinados por el gobierno y el Congreso Nacional para esa transformación, sino por el predominio de unas concepciones tradicionales sobre el diseño del instrumento militar entre los miembros de la conducción 
castrense - cuya última reforma importante se remontaba a la década de 1960. ${ }^{(11)}$ Excepciones a ese abrumador conservadurismo fue el fortalecimiento de unidades de características flexibles y rápido desplazamiento como la IV Brigada Aerotransportada de Córdoba y la creación del "Elemento de Experimentación de Asalto Aéreo" en 1995. ${ }^{(12)}$ Estos últimos tipos de unidades militares fueron visualizadas como un nuevo modelo militar para el siglo XXI también por los legisladores del Partido Justicialista y la Unión Cívica Radical que elaboraron y sancionaron en 1998 la Ley de Reestructuración de las Fuerzas Armadas, aun cuando, es preciso decirlo, ni el presidente Carlos Menem ni su sucesor - el radical Fernando de la Rúa (1999-2001) - la reglamentaron y, en consecuencia, no instrumentalizaron las decisiones políticas ni asignaron los recursos presupuestarios necesarios para implementarla.

El Jefe del Estado Mayor del Comando de Aviación Naval de la Armada, capitán de navío Jorge Luis Colombo, en "Fuerzas Armadas Latinoamericanas. Buscando el mercado adecuado", decía que: "[...]los militares de esta parte del mundo no alcanzan a percibir que pueden perder una parte significativa de sus capacidades reales y de su inserción en la sociedad, si persisten en ver su rol futuro como una simple variación del que tuvieron en el pasado[...]" (COLOMBO, 1993, p. 21). Por ello señalaba que los países latinoamericanos debían definir misiones a sus Fuerzas Armadas sin atender a las "veladas intensiones" de los Estados Unidos, que pretendía unificarlas como "Fuerzas Regionales". Para Colombo, las Fuerzas Armadas poseían misiones "atemporales" como "[...]la garantía permanente de la soberanía e independencia nacionales, la protección de los recursos del país, la preservación de la capacidad de autodeterminación, la defensa común y la integridad territorial [...]" (COLOMBO, 1993, p. 21). Ahora bien, contrariamente a esa necesidad de definiciones, sostenía que en la Argentina los "objetivos estratégicos en el largo plazo" del país y el rol de sus Fuerzas Armadas carecían "de las debidas precisiones". Fundamentalmente criticaba lo que denominaba como una "inversión" de "roles", esto es, que las "misiones secundarias" devinieran por su importancia fáctica en "principales" y que, en consecuencia, los militares acabasen cumpliendo principalmente funciones de seguridad pública

"[...] corriendo narcotraficantes y llevando gente de un lado a otro en camión, en bote o en avión, resultando al mismo tiempo increíblemente poco disuasivas [...]" (COLOMBO, 1993, p. 21-22). Con tal apreciación no rechazaba los "roles no tradicionales" como "[...] combatir al narcotráfico, al narcoterrorismo y quienes atentan contra el medioambiente, o contra la estabilidad de las democracias amenazadas, ya sea a través de organizaciones locales, regionales o extraterritoriales [...]". Cuestionaba la pretensión norteamericana por erigir esas "misiones secundarias" en "principales" (COLOMBO, 1993, p. 21-22).

La intervención de Colombo permite comprender las discusiones políticas y doctrinarias de la época, pues si bien las "nuevas amenazas" fueron instaladas como un paradigma de alcance hemisférico por los Estados Unidos con apoyos de dirigentes políticos y especialistas civiles latinoamericanos; también es preciso decir que las apropiaciones que hicieron

(11) Sobre la persistencia del instrumento militar heredado del siglo XX: LAFFERRIERE \& SOPRANO (2014a).

(12) Denominado "Batallón de Asalto Aéreo Núcleo" desde 1998. 
las conducciones castrenses de los países de esas región de las ideas de aquel paradigma no resultaron unilaterales ni taxativas. Por ende, continuaron reivindicando que su misión principal estaba asociada con amenazas externas, especialmente de otras Fuerzas Armadas; y, simultáneamente, propiciaron una activa participación militar en el combate al narcotráfico, el terrorismo o narcoterrorismo, reconociéndolos como amenazas externas no estatales que podían - desde su punto de vista - subsumirse en la Ley de Defensa Nacional, o bien como amenazas internas a la democracia - violentando la diferenciación entre defensa y seguridad interior. ${ }^{(13)}$

Por su parte, el comodoro Oscar E. Rodríguez Lavalle, oficial superior de la Fuerza Aérea, en "De la seguridad nacional a una doctrina de defensa", criticaba la obsolescencia del Decreto-Ley 16.970 de 1966 sobre las "Bases jurídicas, orgánicas y funcionales para la preparación y ejecución de la defensa nacional" - sancionado por el gobierno de facto del teniente general Juan Carlos Onganía - y reclamaba una nueva doctrina de la defensa. Esta última afirmación resulta significativa pues - como hemos dicho - en 1988 el Congreso Nacional sancionó la Ley de Defensa Nacional que, precisamente, definía esa nueva concepción desde su artículo 2º sosteniendo: "La Defensa Nacional es la integración y la acción coordinada de todas las fuerzas de la Nación para la solución de aquellos conflictos que requieran el empleo de las Fuerza Armadas, en forma disuasiva o efectiva, para enfrentar las agresiones de origen externo". ${ }^{(14)}$ El comodoro reconocía la vigencia de esa Ley, pero entendía que no precisaba la "finalidad de las Fuerzas Armadas". ¿Qué quería decir con ello? Que esa finalidad no podía establecerse por medio de "hipótesis de guerra o de conflicto" - conforme al artículo 8 de la Ley - pues esto inducía a la "engañosa certeza de que todos los conflictos pueden ser previstos o evaluados en tiempo oportuno por un planificador razonable". La estrategia militar debía "contrarrestar capacidades que pueden ser utilizadas en nuestro perjuicio" antes que definir "conflictos puntuales cuyo desarrollo es altamente imprevisible". En definitiva decía que: "La idea de las hipótesis de guerra (de tan negativas connotaciones) como criterio de diseño del instrumento militar debería dar paso al concepto de las capacidades necesarias" (RODRÍGUEZ LAVALLE, 1993, p. 22). Con estos originales argumentos en favor del planeamiento por "capacidades", el Comodoro buscaba incorporar una nueva concepción que sólo adquirió reconocimiento político más de una década después (en la norma, no así en la práctica) con el Decreto 1.729 de 2007 de "Ciclo de Planeamiento de la Defensa Nacional" (ANZELINI y POCZINOK, 2014).

Si estos eran los puntos de vista de oficiales superiores de las Fuerzas Armadas en relación con la reforma de la defensa en la Argentina ¿cuáles eran las perspectivas de los funcionarios civiles del Ministerio de Defensa? En "Buscando nuevos roles para los Ejércitos de América Latina”, del n. 4 de septiembre de 1993, el Subsecretario de Política y Estrategia del Ministerio de Defensa de la Argentina, Virgilio Beltrán, definió cómo debían ser las Fuerzas Armadas Latinoamericanas:

(13) En SOPRANO (2015) se demuestra a través de un análisis de los artículos de oficiales del Ejército Argentino en la Revista de la Escuela Superior de Guerra de esa fuerza cómo hasta el año 1992 se continuó publicando textos abiertamente expresivos de la concepción de la "doctrina de la seguridad nacional" y, con posterioridad, se afirmaron los enfoques destinados a atender a las "nuevas amenazas" al menos hasta 2001. Dicho trabajo destaca cómo los oficiales autores de esos artículos cuestionaban entre las décadas de 1980 y 1990 los fundamentos de la diferenciación entre defensa nacional y seguridad interior que establecieron las leyes homónimas de 1988 y 1991.

(14) Ley 23.554 de Defensa Nacional. http://www.infoleg.gob.ar Consultada en línea el 6 de agosto de 2015. 
a) Basadas en un cuadro profesional en servicio activo y fuerzas de reserva de rápida y fácil movilización [...]; b) Con fuerte orientación hacia los valores cívicos y subordinados al poder político; c) Conducidas por cuadros de oficiales y suboficiales de alta capacitación, no sólo profesional militar sino terciaria y universitaria [...]; d) Reducido en sus dimensiones pero muy flexible, versátil y móvil. Apto para operaciones conjuntas (Joint Operations) y combinadas (Combined Operations), con fuerzas armadas de otros países; e) Con equipamientos diferentes según misiones [...]; f) Con una amplia base de reclutamiento. Con promociones y posiciones asignadas con criterios exclusivamente meritocráticos; g) Con menos referencia a valores puramente institucionales, es decir, con mayor comunión con los valores generales de la sociedad, manteniendo siempre el núcleo duro e irreductible de las pautas de comportamiento militar, fundadas en su misión de aplicar la violencia del Estado en combate (BELTRÁN, 1993b, p. 39).

En el marco de ese modelo las misiones militares serían:

a) Las tradicionales o convencionales de defensa de la soberanía nacional, de los intereses vitales y de recursos naturales de su país. A éstas se agregan la vigilancia general del territorio y fronteras, defensa de los gobiernos legítimos, exploración y ocupación de áreas de difícil acceso (desiertos, selvas, zonas polares etc.); b) La participación en misiones militares combinadas de defensa regional, cuando se establezcan sistemas colectivos de seguridad viables en la región; c) Misiones de conservación de la paz, interposición, humanitarias, de vigilancia etc. o de preservación o restablecimiento del orden jurídico internacional (peace enforcing), fuera del territorio nacional y bajo autoridad internacional (ONU) (BELTRÁN, 1993b, p. 43).

En tanto que el "proceso de modernización" de las Fuerzas Armadas Argentinas demandaría:

a) La organización de unidades militares muy versátiles y flexibles para componer unidades mayores, tipo 'fuerza de tareas', aptas para cumplir las variadas misiones que les puedan ser asignadas. Una o más unidades o estructuras (Ingenieros, Comunicaciones, Acción Psicológica, Contrainsurgencia etc.) serían la columna vertebral, según el compromiso a enfrentar. b) El armamento y equipo sería convencional [...]. La elaboración de nuevas normas de empleo en la acción (Rules of Engagement) en cada caso [...]; c) El despliegue de las fuerzas no sería territorial, sino concentrado en centros de asentamiento e instrucción, con movilidad suficiente para ser empleadas en cualquier punto del territorio. La existencia de la lucha antisubversiva constituye una clara excepción a este principio. La mayor potencia de fuego y los medios de desplazamiento y apoyo deben compensar la disminución en el número de efectivos (BELTRÁN, 1993b, p. 43).

Cabe reparar cómo persistía en esta definición de las misiones del instrumento militar la invocación a la "contrainsurgencia" y la "lucha antisubversiva" que, si bien podía ser en la época un hecho de consideración en Peru, Colombia o Bolivia, no lo era en el Cono Sur, aún cuando en la Argentina el "copamiento" o "asalto" al Regimiento de Infantería Mecanizado 3 de La Tablada del 23 y 24 de enero de 1989 por parte del Movimiento Todos por la Patria fue interpretado como un "rebrote subversivo" por la conducción militar. Asimismo en "El instrumento militar de la defensa", del n. 6 de agosto de 
1994, un Beltrán que entonces había dejado de ser Subsecretario de Política y Estrategia planteaba que la reestructuración de la defensa requería una nueva "concepción" del empleo del instrumento militar, así como "cambios mentales" y "doctrinarios radicales". Dichos cambios no eran meros recortes presupuestarios sino unos en favor de un:

[...] aumento de las capacidades operativas que resulte del sinergismo causado por el efectivo planeamiento conjunto, los mejores sistemas de C3+I [Comando, Control y Comunicaciones más Inteligencia], la interoperatividad interfuerzas, la mayor potencia de fuego, el uso de munición guiada y demás rasgos coherentes con el modelo. Las fuerzas conjuntas deben desarrollar la capacidad de formar 'paquetes' o fuerzas de tareas ad hoc para situaciones emergentes, dentro de un esquema general con: a) fuerzas de reacción inmediatas; b) fuerzas de reacción rápida; y c) organizaciones de aumento, en orden según su grado de alistamiento y tamaño (BELTRÁN, 1994, p. 23).

Esas transformaciones demandarían previsiones presupuestarias estables en el mediano plazo que no deberían ser superiores a las que la defensa nacional contaba por entonces, ya que podía estimarse que "una actitud disuasivo-defensiva en el marco de una naciente seguridad cooperativa, baja los costos de la defensa en su dimensión militar" (BELTRÁN, 1994a, p. 23). ${ }^{(15)}$

A su vez, en el artículo "Actualidad de la defensa en Argentina", del n. 6 de agosto de 1994, el Ministro de Defensa Oscar Camilión definía como misión fundamental de la defensa asegurar la "integridad territorial, ante amenazas y ante riesgos". Para cumplir con dicha misión las Fuerzas Armadas no podían transformarse en meras "fuerzas policiales sofisticadas". Así pues, el ministro cuestionaba a quienes confundían "[...] este estado feliz de paz estructural, con la posibilidad de que la función central de las fuerzas armadas deje de ser la defensa del territorio y del patrimonio nacional [...]" (CAMILIÓN, 1994, p. 10). Una vez más constatamos cómo aún cuando se instalaba en América Latina una agenda de defensa que privilegiaba las "nuevas amenazas", las conducciones del Ministerio y de las Fuerzas Armadas continuaban reivindicando como misión principal conjurar y repeler agresiones estatales externas.

Asimismo teniendo en cuenta que la política de defensa argentina era "defensiva" y "disuasiva", es decir, que debía mostrar capacidades militares suficientes para disuadir eventuales amenazas externas, Camilión consideraba que esa política en el escenario regional de paz y cooperación no colisionaban con la decisión de invertir en medios y equipamientos destinados a mantener la "[...] condición razonable de disuasivo que preserva la paz de una región" y garantizar "el equilibrio frente a los otros países que son sujetos activos de la política en el ámbito territorial en el que nos desenvolvemos [...]" (CAMILIÓN, 1994, p. 11). Por último ¿cuáles serían las funciones militares en los años venideros? El ministro invocaba las siguientes:

(15) Desde la apertura democrática en diciembre de 1983 la dirigencia política argentina con representación en el Congreso y en el Poder Ejecutivo Nacional no otorgó prioridad a los recursos requeridos para la defensa nacional. Dicha situación se objetivó en la evolución de la participación del gasto de defensa sobre el gasto total del Estado nacional (debajo del 5\%), respecto del Producto Bruto Interno (debajo del 1\%) y en su composición (alrededor de un 80\% destinado a la erogación de salarios y retiros militares). 
1. La participación en misiones internacionales de paz en el marco de Naciones Unidas - una misión subsidiaria - convertida progresivamente en una "tarea central", pero que no debía desplazar el rol principal de las Fuerzas Armadas en la defensa contra amenazas externas.

2. La participación militar en misiones de seguridad pública restringida por las Leyes de Defensa Nacional y Seguridad Interior, pues el Estado contaba con fuerzas de seguridad federales con competencia en esos asuntos. ${ }^{(16)}$

3. La participación militar en tareas de defensa civil se incrementaría debido a que el proceso de "privatización masiva" del sector público provocó el cierre o reducción de organismos estatales civiles con capacidades para "enfrentar siniestros". En consecuencia, ante una inundación o terremoto las Fuerzas Armadas eran "[...] la única organización que en este momento está en condiciones de operar de una manera más o menos eficaz y centralizada ante un riesgo de este tipo [...]" (CAMILIÓN, 1994, p. 12-15).

Finalmente, señalemos que en el n. 6 de "SER en el 2000" irrumpió una problemática importante que en 1994 se instaló decididamente en la agenda pública tras el asesinato en una unidad militar del soldado conscripto Omar Carrasco: el pasaje del servicio militar obligatorio al servicio militar voluntario. El asesor del bloque de la Unión Cívica Radical en el Congreso Nacional, José Manuel Ugarte, publicó "Reclutamiento de tropa en Argentina: dar forma al sistema elegido por la sociedad". ${ }^{17)}$ Partía de un presupuesto fundamental: carecía de sentido cualquier discusión a favor de un sistema ideal de reclutamiento de tropa si se desconsideraba el "consenso de la sociedad". Personalmente se mostraba partidario de un sistema mixto que combinara tropa voluntaria y conscriptos cuando fuera preciso, pero entendía que ni la dirigencia política y ni la sociedad argentina estaban dispuestos a sostener este último sistema. Para que el nuevo proveyera recursos humanos eficaces era preciso: a) una adecuada selección de personal; b) estímulos para que los soldados voluntarios se incorporen al personal de cuadros como suboficiales; c) facilitar la reinserción en medios civiles de los voluntarios al finalizar su prestación; d) beneficios sociales compensatorios por las exigencias demandas por el servicio; e) adiestramiento, instrucción y formación. De acuerdo con Ugarte el nuevo sistema voluntario presentaba dos problemas. Uno era la conformación de "reservas", esto es, si sólo se integrarían con oficiales y suboficiales en situación de retiro y soldados

(16) Camilión rechazaba el involucramiento de las Fuerzas Armadas en seguridad pública, especialmente, en la "lucha contra el narcotráfico", aún cuando fuera legítimo que otros países recurrieran a los militares cuando éste amenazaba la "integridad territorial, es decir, a la geografía bajo control del Estado soberano" o cuando no disponían de "organismos especializados como nuestra Gendarmería o nuestra Prefectura" (CAMILIÓN, 1994, p. 12).

(17) Virgilio Beltrán también publicó un breve artículo - "Estrategia y servicio militar" - en el n. 6 mostrándose a favor del nuevo sistema de soldados voluntarios, pero recomendando como necesaria la implementación de un progresivo proceso de transición de un sistema a otro; y se publicó el documento producido por el Estado Mayor Conjunto de las Fuerzas Armadas "Propuesta para implementar el servicio militar voluntario", en el cual se destacaba que las Fuerzas Armadas venían debatiendo y diseñando alternativas de sistemas de reclutamiento voluntario tras la derrota en la Guerra de Malvinas. En tanto que en el n.7 de marzo de 1995 se incluyó el texto de la Ley de Servicio Militar Voluntario aprobada por el Congreso de la Nación en diciembre de 1994. Para un análisis de los proyectos de Ley de Servicio Militar Voluntario, el debate parlamentario sobre la suspensión de la conscripción y el diseño del nuevo sistema voluntario, y un estudio de aspectos cuanti y cualitativos implicados: LAFFERRIERE y SOPRANO (2014b). 
voluntarios que concluyeron sus prestaciones; o si también se incorporarían ciudadanos mayores de 18 con algún entrenamiento breve y próximo a sus lugares de residencia. El otro problema estaba asociado con el anterior: si no se exigiría a los ciudadanos un mínimo de instrucción militar, la defensa quedaría exclusivamente en manos de profesionales. Esta última alternativa no sólo limitaba la disponibilidad de recursos humanos en caso de conflicto; también desalentaba la figura republicana de las "milicias" y del "ejército ciudadano".

\section{CONCLUSIONES}

La represión a los militares que participaron del "levantamiento carapintada" en diciembre de 1990, cumplida por el general Martín Balza, garantizó la subordinación militar efectiva a las autoridades civiles electas y la clausura de las violentas disputas facciosas internas en las Fuerzas Armadas. ${ }^{(18)}$ Con la presidencia de Carlos Saúl Menem se abrió entonces la oportunidad de avanzar desde un esquema de relaciones civiles-militares centrado en el objetivo de la subordinación militar y el control civil (que había predominado en la presidencia Raúl Alfonsín entre 1983 y 1989) al desafío de construir una conducción política de la defensa y su instrumento militar. ${ }^{(19)}$ Las Leyes de Defensa Nacional (1988) y de Seguridad Interior (1991) constituyeron los pilares políticos, jurídicos y doctrinarios clave en esa nueva etapa. ${ }^{(20)}$

A través del análisis de la revista "Seguridad Estratégica Regional en el 2000", hemos visto que la agenda de la defensa nacional y seguridad internacional definida en ese nuevo contexto nacional y escenarios internacional y regional de la década de 1990, comprendía debates sobre temas específicos relativos a la reestructuración o reforma del sistema de defensa y de su instrumento militar. En las perspectivas de políticos con funciones ejecutivas y legislativas, funcionarios civiles y militares, académicos y profesionales, las Fuerzas Armadas no eran ya una amenaza al orden democrático. La subordinación militar asegurada permitía pensar y debatir cuáles serían sus misiones en la política externa y de defensa en los nuevos escenarios internacional y regional, así como su específica incorporación en el proceso de ajuste fiscal y reestructuración estatal denominado como "modernización del Estado".

(18) Sobre los "levantamientos carapintada": LÓPEZ (1994); SAIN (1994); PUCCIARELLI (2006). En la década de 1990 también contribuyeron a asegurar el orden en las Fuerzas Armadas y su subordinación al poder político la sanción de las "leyes de impunidad" - Punto Final (1986), Obediencia Debida (1987) y los indultos del Presidente Menem en 1989-1990 a militares responsables por crímenes de lesa humanidad durante la dictadura, por la conducción de la Guerra de Malvinas y por los "levantamientos carapintada" de 1987-1988. Ahora bien, como mostró la ulterior declaración nulidad de las Leyes de Punto Final y Obediencia Debida por el Congreso de la Nación en 2003 y la inconstitucionalidad de los indultos por crímenes de lesa humanidad por la Cámara de Casación Penal en 2006 y por la Corte Suprema de Justicia en 2010, la inscripción militar en democracia hacia principios del siglo XXI ya no requería de aquellas prerrogativas legales.

(19) Para un análisis de la política de defensa y militar de Raúl Alfonsín: BATTAGLINO (2010).

(20) El diseño de las leyes fundamentales de la defensa se completaría con las Leyes de Servicio Militar Voluntario (1994), Reestructuración de las Fuerzas Armadas (1998) e Inteligencia Nacional (2001). En la concepción de esas cinco leyes tuvieron un rol decisivo legisladores nacionales de los partidos políticos mayoritarios, la Unión Cívica Radical y el Partido Justicialista. Para un estudio sistemático de ese corpus legal: UGARTE (2003). 
¿Qué reformas del sistema de defensa nacional y sus Fuerzas Armadas propiciaban los civiles y militares que publicaron en "SER en el 2000"? Básicamente unas destinadas a garantizar:

1. El cumplimiento efectivo de la "misión principal" de las Fuerzas Armadas contra amenazas estatales externas y, simultáneamente, el desarrollo de "misiones secundarias" o "subsidiarias" atendiendo a las "nuevas amenazas" emergentes en los escenarios de la pos-Guerra Fría, tales como narcotráfico, terrorismo, narcoterrorismo, pobreza, migraciones masivas, catástrofes naturales o antrópicas, conflictos étnicos, religiosos y/o nacionales. La creciente importancia atribuida a estas últimas amenazas, no depreciaba la centralidad otorgada por las conducciones política y militar de los países suramericanos a la "misión principal", aún cuando esta decisión colisionaba con el privilegio reconocido por los Estados Unidos a la securitización de la agenda de defensa en América Latina.

2. Los avances en los procesos de construcción de confianza mutua, cooperación e integración en defensa nacional y seguridad regional a nivel bilateral, Mercosur más Chile y de América del Sur; pero también el mantenimiento de capacidades militares en cada país que permitan conjurar y repeler amenazas estatales externas procedentes de potencias extra-regionales $u$ otras surgidas en países de la región como resultado de crisis políticas o socio-económicas o consecuencia de la exacerbación del militarismos y/o nacionalismos. En ambos casos se propiciaban los beneficios de un accionar coordinado entre los Estados tendiente a asegurar la estabilidad y la paz en la región.

3. Fuerzas Armadas modernizadas con un diseño de organizacional y funcional flexible, de gran movilidad, potencia de fuego, con incorporación de equipamiento y tecnología avanzada, recursos humanos altamente capacitados, preparadas para el accionar militar conjunto entre sus servicios y combinado entre fuerzas de diferentes países en escenarios de cooperación regional e internacionales de participación en misiones de paz con fuerzas multinacionales en el marco de la ONU.

4. Tales reformas debían ser acompañadas por los recursos presupuestarios necesarios que solventasen sus objetivos, pues una reestructuración del sistema de defensa y de su instrumento militar no podía ser reducida a un mero ajuste fiscal producto de las políticas económicas neoliberales impulsadas por el gobierno nacional. Asimismo, como apuntaran editores y algunos especialistas que intervinieron en los debates de la revista "SER en el 2000", en ese nuevo esquema de relaciones civiles-militares con subordinación militar desplegado en la Argentina desde 1990, aquellas reformas constituían ante todo una responsabilidad y un desafío de la dirigencia política. Y para lograrlo era preciso que esos dirigentes y sus asesores civiles no sólo explicitaran su voluntad reformadora sino que contaran con adecuadas capacidades institucionales y conocimientos técnicoprofesionales específicos para realizarlas.

La conducción política civil de la defensa en la Argentina en los albores del siglo XXI, sin embargo, continuó siendo deficitaria. Recién entre los años 2006 y 2009 con la gestión de la ministra de Defensa Nilda Garré - durante las presidencias de Néstor 
Kirchner y de Cristina Fernández de Kirchner - la reforma del sistema se profundizó con la reglamentación de la Ley de Defensa Nacional - dieciocho años después de su sanción en 1988. ${ }^{(21)}$ Y si bien esta etapa histórica del nuevo siglo no constituye el objeto de este artículo - nos hemos ocupado de ella en un libro de nuestra autoría ${ }^{(22)}$ - una breve enumeración de sus fundamentos permitirá reconocer sus principales orientaciones sobre la base de lineamientos políticos establecidos en el país desde la apertura democrática en de diciembre de 1983. Así pues:

1. Se reafirmó un concepto de defensa nacional "defensiva", "autónoma" y "cooperativa" orientada para conjurar "agresiones de origen externo perpetradas por Fuerzas Armadas pertenecientes a otro/s Estado/s" y de acuerdo con la Resolución 3.314 de Naciones Unidas del año 1974. ${ }^{(23)}$ La seguridad interior quedó entonces fuera de la órbita de las Fuerzas Armadas, exceptuando aquellas situaciones puntuales previstas por la Ley de Seguridad Interior. ${ }^{(24)}$ Se mantuvo la distinción entre "misión principal" y "misiones subsidiarias", especificándose estas últimas en torno de cuatro tipos de operaciones: misiones de paz en el marco de Naciones Unidas, de apoyo a la seguridad interior, de apoyo a la comunidad y "países amigos", y contribuyentes a la formación de un sistema de defensa regional. Cabe señalar que estas precisiones programáticas no impidieron que las propuestas de sectores de la dirigencia política y de las conducciones castrenses continuaran recurrentemente reclamando un mayor involucramiento directo de las Fuerzas Armadas en asuntos de seguridad interior.

2. La dimensión "cooperativa" de la defensa nacional fue proyectada en relación con el diseño y realización de ejercicios combinados con países del Mercosur más Chile y, más ampliamente, en el ámbito de la Unión de Naciones Suramericanas. Sin embargo, la participación argentina en estos ejercicios combinados ha sido crecientemente deficitaria, esto es, ponderada positivamente en términos discursivos por las autoridades civiles y militares nacionales, pero escasamente

(21) La Ley de Defensa Nacional se reglamentó con la aprobación de los decretos 727 de Reglamentación de la Ley de Defensa Nacional (2006), 1.691 Directiva sobre Organización y Funcionamiento de las Fuerzas Armadas (2006), 1.729 definiendo el Ciclo de Planeamiento de la Defensa Nacional (2007), 788 sobre las Estructuras Organizativas de la Secretarías del Ministerio de Defensa (2007) y 1.451 modificando el Organigrama y Objetivos del Ministerio (2008), 1.714 fijando la Directiva de Política de Defensa Nacional (2009) y 1.736 estableciendo el Procedimiento de promoción, permanencia en el grado o eliminación del Personal Militar dentro de la categoría de Oficial Superior (2009). También se dio impulso a la desmilitarización de funciones y organismos otrora dependientes de las Fuerzas Armadas, que pasaron a la órbita del Ministerio de Defensa (Servicio Meteorológico Nacional, Servicio de Hidrografía Naval, Instituto Geográfico Nacional, entre otros) y del Ministerio de Planificación Federal, Inversión Pública y Servicios o del Ministerio del Interior y Transporte (Administración Nacional de Aviación Civil).

(22) Véase: LEFFERRIERE y SOPRANO (2015).

(23) El artículo 3 del decreto 727 del año 2006 estableció que: "El Sistema de Defensa Nacional no podrá contemplar en su formulación doctrinaria, en la planificación y adiestramiento, en la previsión de adquisiciones de equipos y/o medios, como así también en las actividades relativas a la producción de inteligencia, hipótesis, supuestos y/o situaciones pertenecientes al ámbito de la Seguridad interior, conforme la misma aparece delimitada en la Ley n. 24.059 de Seguridad interior".

(24) Dichas situaciones excepcionales son operaciones de apoyo a las Fuerzas de Seguridad por requerimiento de un Comité de Crisis y explícita autorización del Ministerio de Defensa, operaciones destinadas a preservar las Fuerzas Armadas y restablecer el orden en jurisdicción militar en caso de atentado a dicha jurisdicción en tiempos de paz, y operaciones que empeñen elementos de combate a requerimiento del Presidente y previo establecimiento del estado de sitio. 
apoyada con recursos materiales y humanos al momento de efectivizarse los compromisos asumidos por el Estado argentino.

3. Se profundizó el desarrollo efectivo de una concepción conjunta del accionar militar, comprendiendo sus implicancias - con desiguales grados de alcance - en diferentes subsistemas de la defensa: doctrina, estrategia y planificación, estructura orgánico-funcional, educación y personal, alistamiento y adiestramiento, logística y equipamiento, infraestructura e información. Y también se produjeron modificaciones en los perfiles profesionales militares avanzando en la implementación de nuevas reformas educativas, de equidad de género, la supresión del Código de Justicia Militar y la sanción del nuevo régimen de justicia y disciplina. Tales reformas procuraron promover la denominada "ciudadanización" de las Fuerzas Armadas, esto es, la comprensión de los militares argentinos como ciudadanos sin prerrogativas morales excepcionales, como funcionarios públicos del Estado nacional y como profesionales especializados en la defensa.

El triunfo en las elecciones nacionales del 22 de noviembre de 2015 de la coalición política de centro-derecha de la Alianza Cambiemos - que llevó como presidente a Mauricio Macri - plantea a los académicos y a los protagonistas civiles y militares de la defensa el desafío de reconocer en qué medida el nuevo gobierno nacional introducirá cambios y/o sostendrá continuidades en estas orientaciones de la política de defensa de la Argentina en el futuro inmediato.

\section{BIBLIOGRAFÍA}

ALVES SOARES, Samuel; SOPRANO, Germán. Políticas de defesa de Argentina e Brasil no começo do século XXI: entre a confiança mútua e as culturas estratégicas em dissonância. En: DOS PASSOS, Rodrigo; VIEIRA, Noemia; LOURENÇAO SIMONETTI, Miriam (Ed.). Relações Internacionais Contemporâneas: novos protagonistas e novas conjunturas, p. 187-210. Marilia: Cultura Acadêmica; Universidade Estadual Paulista; CAPES; Oficina Universitaria, 2014.

ANZELINI, Luciano; POCZINOK, Iván. El planeamiento estratégico militar en la Argentina (20032013): reflexiones en torno al gobierno político de la defensa. Austral. Revista Brasileira de Estratégia e Relações Internacionais, v. 3 n. 6, p. 143-167. Porto Alegre: Universidade Federal do Rio Grande do Sul, 2014.

BALZA, Martín. La seguridad regional. En: SER en el 2000, n. 4, p. 61-62. Buenos Aires: SER en el 2000, 1993a.

BALZA, Martín. El Ejército Argentino en el Futuro. En: SER en el 2000, n. 3, p. 19-20. Buenos Aires: SER en el 2000, 1993b.

BALZA, Martín. Las misiones de los Ejércitos. En: SER en el 2000, n. 1, p. 85-86. Buenos Aires: SER en el 2000, 1992.

BATTAGLINO, Jorge. La política militar de Alfonsín: la implementación del control civil en un contexto desfavorable. En: GARGARELLA, Roberto; MURILLO, María Victoria; PECHENY, Mario (Comps). Discutir Alfonsín, p. 161-184. Buenos Aires: Siglo Veintiuno, 2010.

BELTRÁN, Virgilio. El instrumento militar de la defensa. En: SER en el 2000, n. 6, p. 21-23. Buenos Aires: SER en el 2000, 1994a. 
BELTRÁN, Virgilio. Estrategia y servicio militar. En SER en el 2000, n. 6, p. 68-69. Buenos Aires: SER en el 2000, 1994b.

BELTRÁN, Virgilio. Buscando nuevos roles para los Ejércitos de América Latina. En: SER en el 2000, n. 4, p. 34-46. Buenos Aires: SER en el 2000, 1993.

BELTRÁN, Virgilio. El concepto de suficiencia defensiva. En: SER en el 2000, n. 1, p. 39-41. Buenos Aires: SER en el 2000, 1992.

BICHENO, Hugh. Al filo de la navaja. La historia no oficial de la Guerra de Malvinas. Buenos Aires: Editorial Sudamericana, 2009.

CAMILIÓN, Oscar. Actualidad de la defensa en Argentina. En: SER en el 2000, n. 6, p. 8-15.Buenos Aires: SER en el 2000, 1994.

CANELO, Paula. ¿Un nuevo rol para las Fuerzas Armadas? Políticos y militares frente a la protesta social, los derechos humanos y la crisis presupuestaria: Argentina (1995-2002). Buenos Aires: CLACSO, 2010. COLOMBO, Jorge L. Fuerzas Armadas Latinoamericanas. Buscando el mercado adecuado. En: SER en el 2000, n. 3, p. 21-27. Buenos Aires: SER en el 2000, 1993.

DEVOTO, Fernando; FAUSTO, Boris. Argentina-Brasil. 1850-2000. Buenos Aires: Suramericana, 2008.

FERRER, Jorge O. Evitar la guerra y mantener la paz. En: SER en el 2000, n. 1, p. 80-84. Buenos Aires: SER en el 2000, 1992.

LACOSTE, Pablo. Las imágenes del otro en las relaciones de la Argentina y Chile (1534-2000). Santiago de Chile: Fondo de Cultura Económica; Universidad de Santiago de Chile, 2003.

LAFFERRIERE, Guillermo; SOPRANO, Germán. El Ejército y la política de Defensa en la Argentina del siglo XXI. Rosario: Prohistoria, 2015.

LAFFERRIERE, Guillermo; SOPRANO, Germán. Vino nuevo en odres viejos. La política de defensa nacional de la Argentina democrática y la configuración de su instrumento militar. En: Revista Brasileira de Estudos Estratégicos, v. 1, n. 3, p. 9-48. Niteroi: INEST, Universidade Federal Fluminense, 2014a.

LAFFERRIERE, Guillermo; SOPRANO, Germán. El servicio militarvoluntario en las Fuerzas Armadas Argentinas entre el final del siglo XX y principios del XXI. En: Conjuntura Austral, v. 5, n. 24, p. 17-44. Porto Alegre: Universidade Federal do Rio Grande do Sul, 2014b.

LÓPEZ, Ernesto; SAIN, Marcelo (comps). "Nuevas amenazas". Dimensiones y perspectivas. Dilemas y desafíos para la Argentina y el Brasil. Bernal: Universidad Nacional de Quilmes, 2003.

LÓPEZ, Ernesto. Ni la ceniza ni la gloria. Actores, sistema político y cuestión militar en los años de Alfonsín. Bernal: Universidad Nacional de Quilmes, 1994.

MARCELLA, Gabriel. Misiones futuras de las Fuerzas Armadas Latinoamericanas y política de los Estados Unidos. En: SER en el 2000, n. 5, p. 49-58. Buenos Aires: SER en el 2000, 1994.

MARTÍNEZ, Pablo. La Reestructuración de las Fuerzas Armadas y el rol del Congreso. La experiencia argentina. La Paz: Centro de Estudios Hemisféricos de Defensa, 2002.

MASSINI EZCURRA, Hernán. La participación argentina en las operaciones de paz. En: SER en el 2000, n. 5, p. 23-30. Buenos Aires: SER en el 2000, 1994.

MONIZ BANDEIRA, Luiz A. Argentina, Brasil y Estados Unidos. De la Triple Alianza al Mercosur. Buenos Aires: Norma, 2004.

POCZYNOK, Iván. La modernización militar en la encrucijada. Seguridad interior, política exterior y agenda económica: su impacto en la dimensión estratégica de la política de defensa y en el diseño de las Fuerzas Armadas Argentinas (1989-1999). Buenos Aires: Escuela de Defensa Nacional, 2014. 
PRIETO VIDAL, Daniel. El debate sobre integración regional y defensa en Chile. En: SER en el 2000, n. 2, p. 36-49. Buenos Aires: SER en el 2000, 1992.

PUCCIARELLI, Alfredo. La República no tiene Ejército. El poder gubernamental y la movilización popular durante el levantamiento militar de Semana Santa. En: PUCCIARELLI, Alfredo (coord.). Los años de Alfonsín ¿El poder de la democracia o la democracia del poder? p. 115-152. Buenos Aires: Siglo Veintiuno, 2006.

RAPOPORT, Mario; MADRID, Eduardo. Argentina-Brasil. De rivales a aliados. Política, economía y relaciones bilaterales. Buenos Aires: Capital Intelectual, 2011.

RODRÍGUEZ LAVALLE, Oscar. De la seguridad nacional a una doctrina de defensa. En: SER en el 2000, n. 3, p. 28-33. Buenos Aires: SER en el 2000, 1993.

RUNZA, Ricardo. Las relaciones argentino-chilenas de defensa. Análisis y evaluación desde la perspectiva del Comité Permanente de Seguridad. En: Lateinamerika Analysen, n. 8, p. 137-166. Hamburg: German Institute of Global and Area Studies, Institute of Latin America Studies, 2004.

RUSSELL, Roberto; TOKATLIAN, Juan Gabriel. El lugar de Brasil en la política exterior argentina. Buenos Aires: Fondo de Cultura Económica, 2003.

SAIN, Marcelo. Los votos y las botas. Estudios sobre la defensa nacional y las relaciones civil-militares en la democracia argentina. Buenos Aires: Prometeo, 2010.

SAIN, Marcelo. Quince años de legislación democrática sobre temas militares y de defensa (1983-1998).

En: Desarrollo Económico, v. 40, n. 57, p. 121-142. Buenos Aires: SER en el 2000, 2000.

SAIN, Marcelo. Los levantamientos carapintada. 1987-1991. Buenos Aires: Centro Editor de América Latina, 1994.

SIMONOFF, Alejandro. Envío de tropas y política exterior (1989-2005). En: Relaciones Internacionales, n. 28, p. 27-155. La Plata: IRI,Universidad Nacional de La Plata, 2005.

SOPRANO, Germán. El Ejército Argentino en democracia: de la "doctrina de la seguridad nacional" a la definición de las "nuevas amenazas" (1983-2001). Revista Universitaria de Historia Militar, v. 4, n. 7, p. 86-107. Cádiz: Centro de Estudios Universitarios de Historia Militar, 2015.

SOPRANO, Germán. La definición de una agenda de defensa para la democracia en Argentina. Trayectorias individuales y experiencias colectivas de políticos, militares y expertos civiles en el seminario y la revista Seguridad Estratégica Regional en el 2000. En: CANCINO, Horacio et al (Eds). Miradas desde la Historia social y la Historia intelectual. América Latina en sus culturas: de los procesos independistas a la globalización, p. 759-776. Córdoba: Centro de Estudios Históricos Profesor Carlos Segreti; Universidad Católica de Córdoba; Universidad Veracruzana, 2013.

TEIXEIRA, Manoel. Sociedad, Fuerzas Armadas y Política de Defensa en Brasil. En: SER en el 2000, n. 2, p. 22-35. Buenos Aires: SER en el 2000, 1992.

UGARTE, José M. Los conceptos jurídicos y políticos de la seguridad y la defensa. Buenos Aires: Editorial Plus Ultra, 2003.

UGARTE, José M. Reclutamiento de tropa en Argentina: dar forma al sistema elegido por la sociedad. En: SER en el 2000, n. 6, p. 65-67. Buenos Aires: SER en el 2000, 1994.

VACA, Eduardo. Reestructuración del sistema de defensa. En: SER en el 2000, n. 8, p. 8-38. Buenos Aires: SER en el 2000, 1995.

VACA, Eduardo. Identidad nacional e integración regional. En: SER en el 2000, n. 2, p. 5-6. Buenos Aires: SER en el 2000, 1992. 